\title{
Bundles in Academic Discourse
}

\begin{abstract}
Ken Hyland
Automated, frequency-driven approaches to identifying commonly used word combinations have become an important aspect of academic discourse analysis and English for academic purposes (EAP) teaching during the last 10 years. Referred to as clusters, chunks, or bundles, these sequences are certainly formulaic, but in the sense that they are simply extended collocations that appear more frequently than expected by chance, helping to shape meanings in specific contexts and contributing to our sense of coherence in a text. More recently, work has extended to "concgrams," or noncontiguous word groupings where there is lexical and positional variation. Together, these lexical patterns are pervasive in academic language use and a key component of fluent linguistic production, marking out novice and expert use in a range of genres. This article discusses the emerging research which demonstrates the importance of formulaic language in both academic speech and writing and the extent to which it varies in frequency, form, and function by mode, discipline, and genre.
\end{abstract}

An important component of fluent linguistic production is control of the multiword expressions referred to as clusters, chunks, or lexical bundles. While perhaps not strictly formulaic by Wray's (2002) definition, which makes a claim that sequences are stored in the mental lexicon, these strings are nevertheless glued together in everyday discourse. Simply put, bundles are statistically the most frequent recurring sequences of words in any collection of texts: extended collocations that appear more repeatedly than expected by chance (Biber, Johansson, Leech, Conrad, \& Finegan, 1999). They are made evident through corpus analysis software that retrieves multiword units with specified frequency and distribution criteria and as a result are neither idiomatic nor, usually, complete grammatical units (Biber, 2006), throwing up strings such as it was found that and in the case of. They are familiar to users of a language and have customary pragmatic or discoursal functions. The criterion of frequency is therefore paramount and distinguishes bundles from, say, Renouf and Sinclair's (1991) collocational frameworks of productive preselected patterns and from fixed idioms.

While some research has been published focusing on academic bundles in languages such as Spanish (e.g., Butler, 1998; Cortes, 2008; Tracy-Ventura, Cortes, 
\& Biber, 2007) and Korean (Kim, 2009), published work on other languages is limited to particular language groups writing in English, such as Chinese (e.g., Ma, 2009; Wei, 2007; Xu, 2007). The vast majority of research looks at academic bundles in English, and therefore this chapter focuses on English, discussing the emerging research which demonstrates the importance of this type of formulaic language in both academic speech and writing and the extent to which it varies in frequency, form, and function by mode, discipline, and genre.

\section{IDENTIFYING BUNDLES: FREQUENCY, DISTRIBUTION, AND VARIABILITY}

Research into lexical bundles follows the pioneering work of Bengt Altenberg (1993, 1998), who created the methodology to identify frequency-defined recurrent word combinations and who combined grammatical and functional analysis in categorizing them. Clearly an approach to identifying and classifying formulaic units based solely on frequency of occurrence and breadth of use has the advantage of being methodologically clear-cut, although researchers have used different frequency and distribution criteria.

The threshold frequency, which determines the number of bundles to be included in the list, has ranged from 10 (Biber et al., 1999; Biber, 2006) to 20 (Cortes, 2004; Hyland, 2008a, 2008b) to 40 times per million words (Biber, Conrad, \& Cortes, 2004). Such normalization methods, which are widely used to compare individual words across different sized corpora, may, however, be unreliable when working with lexical bundles, and more research is needed to establish their validity. Moreover, analysts using smaller spoken corpora often employ much lower cutoffs (De Cock, 1998; Nesi \& Basturkmen, 2006), but it can be very problematic to determine what a bundle is in very small corpora. This raises a larger issue of using small samples in the study of bundles, as small corpora tend to produce many more bundles than their larger counterparts in the same registers. Thus, further research is needed before reliable comparisons are made.

A second identification criterion is that sequences have to occur in a specified number of files in the corpus, such as three to five texts (e.g., Biber \& Barbieri, 2007) or 10 percent of texts (Hyland, 2008a) to avoid the quirks of individual speakers or writers. Finally, analysts must decide on the length of strings they select. Three-word bundles are extremely common, and tend not to be very interesting, while 5- and 6-grams are comparatively rare and often subsume shorter ones. Four-word bundles seem to be most often studied, perhaps because they are over 10 times more frequent than five-word sequences and offer a wider variety of structures and functions to analyze. Biber et al. (1999), in fact, suggested that four-word bundles and above "are more phrasal in nature and correspondingly less common" (p. 992).

In terms of analysis, researchers often manually exclude bundles with noun phrases as being too text-dependent and remove overlapping word sequences where two four-word bundles are actually part of a five-word string (e.g., it has been suggested and has been suggested that; Chen \& Baker, 2010). Frequency analysis, moreover, produces long lists of recurrent word sequences that often 
run counter to intuition. Sequences such as on the other hand and the results suggest appear psycholinguistically unproblematic compared to at the end of and is one of the, which have similar frequencies. Some researchers have therefore chosen to weed out nonintuitive expressions to produce shorter lists which include only units of "structural and idiomatic coherence" (Simpson, 2004, p. 42), although this is a method vulnerable to claims of subjectivity.

Others have relied upon complex combination of "corpus statistics, linguistic analyses, psycholinguistic processing metrics and instructor insights" to produce "psycholinguistically salient sequences" for teaching purposes (SimpsonVlach \& Ellis, 2010, p. 490). One aspect of this is often the mutual information (MI) score, which is a statistical measure of association between words in a bundle. Programs such as Collocate (Barlow, 2004) compute this score automatically to indicate the strength of collocations, comparing the frequency of a word combination to the overall frequencies of each of the individual words. The method has been used in several studies (e.g., Ellis, Simpson-Vlach, \& Maynard, 2008; Simpson-Vlach \& Ellis, 2010) as it appears to offer an indication of phrasal coherence, corresponding to distinctive functions or meanings. MI scores, however, were originally conceived for two-word collocations and may be unreliable when trying to account for the frequency of longer expressions. It tends to privilege low-frequency items and simply reflects a likelihood that a pair of words will occur together, regardless of order (Biber, 2009).

Moreover, the automated, frequency-driven means of retrieving lexical bundles allows us to say little about how such sequences are psycholinguistically processed (e.g., Wray, 2002) or acquired (e.g., Schmitt, Dornyei, Adolphs, \& Durow, 2004). Their recurrence in multiple texts by different users, however, suggests at least some perceptual salience among users and conventionalization within a particular discourse community. The fact they are identified through corpus-driven research means that they emerge inductively from analysis of a corpus rather than the a priori assumptions of the analyst. Indeed, they are a key way of shaping text meanings and contributing to our sense of distinctiveness in a register. Thus the presence of extended collocations like as a result of, it should be noted that, and as can be seen help identify a text as belonging to an academic register while with regard to, in pursuance of, and in accordance with are likely to mark out a legal text.

Clearly, bundles refer only to fixed collocational patterns, yet our intuitions suggest that there is considerable positional flexibility in formulaic sequences, and Biber (2009) noted various pattern types in particular four-word combinations. While software like WordSmith Tools 5 (Scott, 2008) is able to generate high-frequency phrases such as the relationship between the, it misses instances of the same pattern in, for example, the clear relationship between the or the uncertain relationship between the. Clearly, some sequences have optional slots in addition to their fixed elements and these remain undiscovered. By revealing noncontiguous word groupings, or concgrams, recent software developments seek to overcome this limitation (Cheng, 2007; Cheng, Greaves, Sinclair, \& Warren, 2007; Greaves, 2009).

According to the program designer, Chris Greaves, a concgram is "all of the permutations of constituency variation and positional variation generated by 
the association of two or more words" (Cheng, Greaves, \& Warren, 2006, p. 414). This is, however, a relatively new way of identifying and categorizing word associations that has yet to generate published studies of academic discourse. Preliminary searches of nonacademic spoken corpora have found that the majority of concgrams are composed of noncontiguous collocations, revealing both constituency $(\mathrm{AB}, \mathrm{ACB})$ and positional $(\mathrm{AB}, \mathrm{BA})$ variations. There is clearly great potential here to illuminate the formulaic patterning, especially phraseological variation, of academic speech and writing.

\section{THE IMPORTANCE AND DISTINCTIVENESS OF ACADEMIC SEQUENCES}

These sequences are important to writers and speakers for at least three reasons (Coxhead \& Byrd, 2007):

(1) Their repetition offers users (and particularly students) ready-made sets of words to work with.

(2) They help define fluent use and therefore expertise and legitimate disciplinary membership.

(3) They reveal the lexico-grammatical community-authorized ways of making-meanings.

Routinely employed sequences, therefore, work to facilitate pragmatically efficient communication, and in academic discourse often function to structure a discourse by guiding readers through a text (in the next section, as shown in figure) or by linking ideas (is due to the, in contrast to). In addition, by signaling appropriate use of disciplinary resources, they allow writers to display solidarity with colleagues (Cortes, 2006) and to construct a disciplinary competent voice (Hyland, 2008a; Pang, 2010).

Lexical bundles, therefore, seem to reflect a very real part of users' communicative experiences. As suggested by Sinclair's (1991) idiom principle, there is a phraseological tendency in language use whereby speakers and writers co-select words in routine ways. Sentences are typically made up of interlocking bundles as words are mentally primed for use with other words through our experience of them in frequent associations (Hoey, 2005). Everything we know about a word is a result of our encounters with it, so that when we formulate what we want to say, the wordings we choose are shaped by the way we regularly come across them in similar texts. Needless to say, these different kinds of lexical patterns are pervasive in academic language use and a key component of fluent linguistic production, marking out novice and expert use in both spoken and written contexts.

Corpus research has identified recurrent patterns in corpora of written and spoken language which occur significantly more frequently in academic than in other, nonacademic registers. This suggests, for example, that academic writing draws on a much larger stock of prefabricated phrases than either news or fiction in the British National Corpus Baby edition, with over 450 different four-word clusters occurring more than 10 times in one million words (Hyland, 2008a); see Table 1. 
Table 1. Ranked Four-Word Bundles in the British National Corpus Baby Edition by Frequency

\begin{tabular}{|c|c|c|c|}
\hline Academic & Fiction & News & Conversation \\
\hline $\begin{array}{l}\text { in terms of the } \\
\text { in the case of } \\
\text { the end of the } \\
\text { on the basis of } \\
\text { as a result of } \\
\text { the way in which } \\
\text { it is possible to } \\
\text { at the end of } \\
\text { per cent of the } \\
\text { the extent to } \\
\text { which } \\
\text { in the context of } \\
\text { at the same time } \\
\text { it is important to } \\
\text { that there is a } \\
\text { a wide range of } \\
\text { it is clear that } \\
\text { one of the most } \\
\text { at the time of } \\
\text { in the form of } \\
\text { as shown in fig } \\
\text { the rest of the } \\
\text { can be used to } \\
\text { in relation to the } \\
\text { the size of the }\end{array}$ & $\begin{array}{l}\text { at the end of } \\
\text { the rest of the } \\
\text { for the first time } \\
\text { at the same time } \\
\text { in the middle of } \\
\text { the edge of the } \\
\text { the top of the } \\
\text { I don't want to } \\
\text { he was going to } \\
\text { the back of the } \\
\text { the other side of } \\
\text { the side of the } \\
\text { in front of him } \\
\text { it would have been } \\
\text { on the edge of } \\
\text { in front of the } \\
\text { the middle of the } \\
\text { what do you think } \\
\text { a cup of tea } \\
\text { on the other side } \\
\text { what do you mean } \\
\text { was going to be } \\
\text { as if he was } \\
\text { he shook his head }\end{array}$ & $\begin{array}{l}\text { at the end of } \\
\text { for the first time } \\
\text { per cent of the } \\
\text { the rest of the } \\
\text { as a result of } \\
\text { one of the most } \\
\text { is one of the } \\
\text { at the same time } \\
\text { in the second half } \\
\text { a member of the } \\
\text { in the first half } \\
\text { is likely to be } \\
\text { by the end of } \\
\text { will be able to } \\
\text { the first time in } \\
\text { the top of the } \\
\text { in an attempt to } \\
\text { the start of the } \\
\text { as well as the } \\
\text { as part of the } \\
\text { at the start of } \\
\text { on the other hand } \\
\text { it would be a } \\
\text { a spokesman } \\
\text { for the }\end{array}$ & $\begin{array}{l}\text { no no no no } \\
\text { do you want to } \\
\text { I thought it was } \\
\text { what do you want } \\
\text { da da da da } \\
\text { thank you very much } \\
\text { I don't know whether } \\
\text { have a look at } \\
\text { are you going to } \\
\text { do you want a } \\
\text { you want me to } \\
\text { what do you think } \\
\text { I don't think so } \\
\text { ha ha ha ha } \\
\text { if you want to } \\
\text { I don't want to } \\
\text { you don't have to } \\
\text { a bit of a } \\
\text { know what I mean } \\
\text { you know what I } \\
\text { oh I don't know } \\
\text { do you want me } \\
\text { I don't know if } \\
\text { or something } \\
\text { like that }\end{array}$ \\
\hline
\end{tabular}

Clearly, in this corpus at least, academic writing shares only a few clusters with either fiction or conversation. These kinds of register differences are confirmed by Biber et al. (1999) and Simpson-Vlach and Ellis (2010) with much larger corpora. In seeking to identify high-frequency academic-specific bundles for teaching purposes, for example, Simpson-Vlach and Ellis list over 200 three-, four-, and five-word bundles which are statistically more common in academic texts than in a large corpus of 15 nonacademic spoken and written genres. The most statistically more frequent being in terms of, at the same time, and from the point of view.

Biber et al. (1999) showed that this distinctiveness extends to the formal properties of bundles, so that academic bundles are frequently preposition + noun phrase fragments, noun phrase + of phrase fragments (see also Hyland, 2008b; Scott \& Tribble, 2006) or anticipatory it fragments (Hyland \& Tse, 2005). Together, these three forms make up over 70 percent of four-word patterns in academic discourse but rarely figure in conversation, where 60 percent of 
Table 2. Common Forms of Four-Word Bundles in Academic Writing

\begin{tabular}{ll}
\hline Structure & \multicolumn{1}{c}{ Examples } \\
\hline noun phrase + of & $\begin{array}{c}\text { the end of the, the nature of the, the beginning of the, a } \\
\text { large number of } \\
\text { the fact that the, one of the most, the extent to which, } \\
\text { other noun phrases } \\
\text { prepositional phrase }+ \text { of } \\
\text { context of } \\
\text { other prepositional } \\
\text { phrases }\end{array}$ \\
$\begin{array}{l}\text { on the other hand, at the same time, in the present } \\
\text { study, with respect to the } \\
\text { fragment } \\
\text { anticipatory it }+ \text { verb/adj } \\
\text { is shown in figure, is based on the, is defined as the, } \\
\text { can be found in }+ \text { noun/adjectival } \\
\text { phrase }\end{array}$ & $\begin{array}{l}\text { it is important to, it is possible that, it was found that, } \\
\text { is should be noted }\end{array}$ \\
others & $\begin{array}{l}\text { result of } \\
\text { as shown in figure, should be noted that, is likely to be, } \\
\text { as well as the }\end{array}$
\end{tabular}

Note. Adapted from Biber et al. (1999, pp. 997-1025).

patterns are personal pronoun + lexical verb phrases (I don't know what, I thought it was) and auxiliary + active verb (have a look at, do you want a). These patterns are therefore strong register discriminators. Table 2 shows the most common patters in academic writing.

\section{FORMULAIC PATTERNS IN SPOKEN AND WRITTEN ACADEMIC DISCOURSE}

Corpus studies have also shown how ubiquitous these bundles are in academic genres. Defining lexical bundles as combinations that recur at least 10 times per million words across five or more texts, Biber et al. (1999) suggested that threeword bundles occur over 60, 000 times and four-word bundles over 5,000 times per million words in academic prose. The lists highlight the fact that many of the most frequent bundles in academic writing are extremely common indeed, and like bundles in other registers, that these frequencies drop dramatically when we look at strings of five words or more. On the other hand was by far the most frequent cluster, which occurred 100 times per million words and was more than twice as common as those next placed, at the same time and in the case of. The top 10 all occurred more than 60 times per million words, and the entire list was dominated by prepositional phrase constructions and noun phrases with of fragments.

The most frequent three-, four- and five-word bundles in a 3.5-million word corpus of articles, $\mathrm{PhD}$ dissertations, and master's theses are shown in Table 3 (Hyland, 2008b). 
Table 3. Most Frequent Three-, Four-, and Five-Word Bundles in Academic Articles and Theses

\begin{tabular}{|c|c|c|c|c|c|}
\hline 3-Word & Freq. & 4-Word & Freq & 5-Word & Freq. \\
\hline in order to & 1,629 & on the other hand & 726 & on the other hand the & 153 \\
\hline in terms of & 1,203 & at the same time & 337 & at the end of the & 138 \\
\hline one of the & 1,092 & in the case of & 334 & it should be noted that & 109 \\
\hline the use of & 1,081 & the end of the & 258 & it can be seen that & 102 \\
\hline as well as & 1,044 & as well as the & 253 & due to the fact that & 99 \\
\hline the number of & 992 & at the end of & 252 & at the beginning of the & 98 \\
\hline due to the & 886 & in terms of the & 251 & may be due to the & 64 \\
\hline on the other & 810 & on the basis of & 247 & it was found that the & 57 \\
\hline based on the & 801 & in the present study & 225 & to the fact that the & 52 \\
\hline the other hand & 730 & is one of the & 209 & there are a number of & 51 \\
\hline in this study & 712 & in the form of & 191 & in the case of the & 50 \\
\hline a number of & 690 & the nature of the & 191 & as a result of the & 48 \\
\hline the fact that & 630 & the results of the & 189 & at the same time the & 41 \\
\hline most of the & 605 & the fact that the & 177 & is one of the most & 37 \\
\hline there is a & 575 & as a result of & 175 & it is possible that the & 36 \\
\hline according to the & 562 & in relation to the & 163 & one of the most important & 36 \\
\hline the present study & 549 & at the beginning of & 158 & play an important role in & 36 \\
\hline part of the & 514 & with respect to the & 156 & can be seen as a & 35 \\
\hline the end of & 501 & the other hand the & 154 & the results of this study & 35 \\
\hline the relationship between & 487 & the relationship between the & 152 & from the point of view & 34 \\
\hline in the following & 478 & in the context of & 150 & the point of view of & 34 \\
\hline the role of & 478 & can be used to & 148 & it can be observed that & 33 \\
\hline some of the & 474 & to the fact that & 143 & this may be due to & 32 \\
\hline as a result & 472 & as shown in figure & 136 & an important role in the & 31 \\
\hline it can be & 468 & it was found that & 133 & in the form of a & 31 \\
\hline
\end{tabular}


It is also clear that many four- and five-word strings, such as on the other hand the and it can be seen that "hold three word bundles in their structure" (Cortes, 2004; p. 401), thus suggesting that three- and four-grams might offer a more productive focus for teachers and analysts. Table 3 also shows that most bundles, unlike idiomatic phrases, are semantically transparent and formally regular, many being nominal or prepositional phrases (cf. Butler, 1998). In particular, we can see the considerable use of what Biber et al. (1999) call noun phrase + postmodifier fragments (the number of, the relationship between the, one of the most important), preposition + of phrase fragments (in terms of, on the basis of, at the beginning of the), as well as anticipatory it fragments (it can be, it was found that, it should be noted).

Studies of bundles in spoken academic discourse have been much rarer and mainly limited to the work conducted by Biber and colleagues at Northern Arizona University (e.g., Biber, 2006; Biber \& Barbieri, 2007; Biber et al., 2004; Cortes \& Csomay, 2007). This research has investigated a range of genres (or "registers" in Biber's parlance) including both instructional (classroom teaching, study groups) and noninstructional contexts (student advising, office hours, class management, and university service encounters). This research shows that while classroom teaching uses an extremely wide variety of different bundles in comparison to conversation, textbooks, and academic prose (Biber et al., 2004), these bundles are even more prevalent and diverse in noninstructional genres such as classroom management and service encounters (Biber \& Barbieri, 2007). Results such as this, however, need to be seen in the context of the preceding comments concerning the reliability of frequencies generated from very small corpora.

There is also a substantial reliance on what Biber called stance bundles, concerned with expressing epistemic evaluations, attitudes, or modal meanings and with framing new propositional information (examples from Biber, 2006):

(1) I want you to take out a piece of paper.

Right now what we're going to take a look at are ones that are [...] positive and beneficial.

All you have to do is work on it.

Cortes and Csomay (2007) suggested that these stance bundles are found particularly at the beginning of university lectures, where teachers are trying to negotiate class management issues, and toward the middle, where they are eliciting class participation. Discourse organizing bundles are also very common in classroom teaching - and in conversation-mainly to introduce and elaborate topics:

(2) What I want to do is quickly run through the exercise ...

Today we are going to talk about testing hypotheses.

It has to do with the START talks, with the Russians.

Simpson (2004) confirmed the importance of interactive expressions in her study of the MICASE (Michigan Corpus of Academic Spoken English) corpus, but highlighted the significance of discourse organizing bundles, particularly those use to summarize, sequence, and focus information. Simpson also, however, 
noted the influence of idiolect and speech event on distributions. Her data also showed a considerable variation in the expressions favored by professors (and so on, in other words, and so forth) and by students (I was like, something like that, you know what I mean) in this U.S. university context.

\section{BUNDLES AND GENRE VARIABILITY}

Despite these apparent differences between spoken and written discourse observed by Biber and colleagues, already mentioned, it is genre, rather than mode, which is more important in distinguishing the distribution of bundles. Biber and Barbieri (2007) made this clear:

The extent to which a speaker or writer relies on lexical bundles is strongly influenced by their communicative purposes, in addition to general spoken/written differences. The explanation for the infrequent use of lexical bundles in the academic written registers (textbooks and academic prose) apparently lies in the restricted communicative goals of those registers-focused on informational communication-rather than the written mode per se. (p. 273)

An important feature of bundles is, therefore, their variation across different genres, and this, in turn, contributes to our understanding of the integrity of generic patterning.

Biber (2006), for example, shows us that the spoken genre of classroom teaching uses about twice as many different bundles as conversation and about four times as many as textbooks. Biber suggested that this extremely high density could be explained by the fact that teaching draws heavily on both oral and written genres. He also found that the bundles are required to do very different jobs in the two genres, with classroom talk comprising much higher proportions of discourse organizers (going to talk about, it has to do with) and stance bundles (I don't know if, I want you to) than textbooks. Similarly, Simpson (2004) and Simpson and Mendis (2003) discovered, perhaps unsurprisingly, almost completely different sets of bundles in monologic (lectures) and dialogic (tutorials, class discussions) genres, with more than twice as many expressions in the interactive speech events (I'll show you, in a minute, in some sense).

This genre variation is repeated in written genres, particularly in published academic papers and student texts. Chen and Baker (2010), for example, discovered a considerable "gap between native expert academic prose and immature student academic writing" (p. 34). This is particularly marked in the high uses of referential bundles, which are used to specify attributes of various kinds in three different ways:

- Framing: in the context of, the existence of the

- Quantifying: a wide range of, the extent to which

- Place/time/text-deictic: are shown in figure, at the same time 
The student texts, on the other hand, contained far more discourse organizers. Chen and Baker (2010) attributed these variations to both proficiency and genre differences, noting more so-called native-like writing among the advanced learners in the corpora. Similarly, Cortes (2004) found that the bundles used by students did not correspond to those employed by professional authors, and that many bundles frequently found in published papers were never used by students at all.

Seeking to control for proficiency, I explored a corpus of 3.5 million words of skilled writing, looking at published articles and at high graded master's theses and doctoral dissertations by second language (L2) writers in Hong Kong (Hyland, 2008a, 2008b). There were considerable differences, with the articles containing 71 different four-word bundles of 20 per million words or more in more than 10 percent of texts; the PhD dissertations, 95 different clusters; and the master's texts, 149. Overall, in fact, the postgrad genres appear to be more phrasal than the published one, with four-word bundles composing 5.1 percent of the master's theses, 3.8 percent of the PhD dissertations, and 3.1 percent of the research articles. While this may suggest a certain conservatism among students and an attempt to rely on less risky prefabricated language (e.g., Hyland \& Milton, 1997), it is also true that the research article has a different purpose, audience, and repertoire of rhetorical features compared to the student genres, representing what Swales (1990) referred to as a norm developing practice, concerned with persuasive reporting through engagement with the professional world, rather than norm developed which largely displays what the student knows.

These differences help explain genre differences in the functions that the bundles were used to perform in these corpora. Based loosely based on Halliday's (1994) linguistic macrofunctions, bundles comprised these broad types:

- Research-oriented (ideational), which help writers to structure their activities and experiences of the real world (at the beginning of, at the same time, in the present study)

- Text-oriented (textual), concerned with the organization of the text and its elements as a message (on the other hand, these results suggest that, in the next section)

- Participant-oriented (interpersonal), which focus on the writer or reader of the text (may be due to, it is possible that, should be noted that)

Table 4 shows that half of all bundles related to the organization of the argument, although with considerable intergenre variation.

The relatively high proportion of text-oriented bundles in the research articles is worthy of comment. This is the most discursively crafted and rhetorically machined genre of the three, and almost two thirds of its clusters present research by engaging with a literature, providing warrants, establishing background, connecting ideas, directing readers around the text, and specifying limitations. The number of resultative markers, for example, shows a high degree of reader awareness as it points to the writer's interpretations and highlights the inferences the writer wants readers to draw: 
Table 4. Distribution of Bundle Functions by Genre (\%) (Hyland, 2008a: p 54)

\begin{tabular}{lcccc}
\hline Genre & $\begin{array}{c}\text { Research } \\
\text { oriented }\end{array}$ & $\begin{array}{c}\text { Text } \\
\text { oriented }\end{array}$ & $\begin{array}{c}\text { Participant } \\
\text { oriented }\end{array}$ & Totals \\
\hline Research articles & 25.5 & 60.3 & 14.2 & 100 \\
PhD dissertations & 34.1 & 54.7 & 11.2 & 100 \\
Master's theses & 48.6 & 42.5 & 8.9 & 100 \\
Overall & 36.1 & 52.5 & 11.4 & 100 \\
\hline
\end{tabular}

(3) The results of the mating experiments clearly indicate the existence of two ISGs in C. subnuda.

(Bio RA)

On the theoretical level, our results suggest that the perspective of opportunism may not axiomatically hold in all asymmetric contexts.

(BS RA)

The high proportion of text-oriented bundles similarly suggest a clear audience orientation among $\mathrm{PhD}$ students, as well as laying claim to a certain disciplinary competence by demonstrating a care with both research and with language. Because the PhD texts were much longer, they also contained text-oriented strings which structured more discursively elaborate arguments over a greater span of text, referring to text stages and announcing discourse goals, as in item four in the following list, or pointing to other parts of the texts to make additional material salient and available to readers in recovering the writer's intentions (item 5):

(4) In an attempt to establish the research context for this inquiry, in section 2.5 , I begin with the research history of language learner strategies and then...

(AL PhD)

In this section we offer evidence on the effect of corporate investment decisions on the market value of the firm.

(BS PhD)

When the system is in normal condition, the computer result is shown in Figure 20 and the voltage profile of the weakest bus is shown in Figure 21.

(EE PhD)

Their styles of being a facilitator will be discussed in the next chapter, indicating the favorable student factors that contributed to being a facilitator.

(AL PhD)

While apparently referential, these clusters have important rhetorical functions by helping to frame, scaffold, and present arguments as a coherently managed and organized arrangement. As such they reflect the writers' awareness of the discursive conventions of a sustained discussion and the processing needs of a particular disciplinary audience. 
The discourse of master's students,' on the other hand, is characterized less by a text-oriented reader awareness than by use of research-oriented bundles and a relatively low use of participant-oriented forms, choices which impart a strong real-world, research-focused sense to their texts. The master's students were the only writers to refer more to their research than its presentation, drawing particularly on those clusters which described research objects or contexts (6) and, in almost 25 percent of cases, those depicting procedures (7):

(5) The structure of the resolver is similar to that of a motor.

(EE MSc) This is the name of the executable file, i.e. "winword," "excel," etc.

(6) Daily spiking was required in order to maintain the tank mercury concentration close to the designated concentration.

(Bio MSc) Parallel processing can be used to carry out the multistation-runs by a number of computers in order to minimize the computation time....

(BS MA)

Interestingly, these preferences also seem to characterize undergraduate writing among native English speakers in the British Academic Written English Corpus (Lee \& Chen, 2009).

The infrequent use of participant sequences is often seen as a defining feature of expository writing by L2 students and perhaps reflects cultural preferences for a noninterventionist stance among these Hong Kong writers (Scollon \& Scollon, 2001). The assertion of an explicit authorial position is, however, a common feature of published academic writing, which is clearly structured to evoke affinity and engagement. Along with their observations and interpretations, writers annotate their texts to comment on the possible accuracy of a claim, the extent they want to commitment themselves to it, or the attitude they want to convey, as here:

(7) However, this may be due to disruption of the complex upon antibody binding, or the antibodies we have used may block the interaction.

(Bio RA)

It is obvious that the partial heat resistances are provided directly by the structure function.

(EE RA)

\section{BUNDLES AND DISCIPLINARY VARIATION}

Studies show that the distribution of bundles not only characterizes particular modes, genres, and authors, but also is a strong disciplinary marker. This is clear from a disciplinary analysis of the research article, thesis, and dissertation corpora discussed earlier in this article (Hyland, 2008b). In terms of frequencies, for example, electrical engineering texts contained the greatest range of bundles with 213 different four-word strings meeting the 20 per million words threshold 
Table 5. Frequency of Bundles by Discipline

\begin{tabular}{lccc}
\hline Discipline & $\begin{array}{c}\text { Different } \\
\text { bundles }\end{array}$ & $\begin{array}{c}\text { Total } \\
\text { cases }\end{array}$ & $\begin{array}{c}\text { \% of total words } \\
\text { in bundles }\end{array}$ \\
\hline Electrical engineering & 213 & 4562 & 3.5 \\
Business studies & 144 & 3728 & 2.2 \\
Applied linguistics & 141 & 4631 & 1.9 \\
Biology & 131 & 2909 & 1.7 \\
\hline
\end{tabular}

(across 10 percent of texts) and also the highest proportion of words in the texts occurring in four-word bundles (Table 5).

Many bundles used by engineers are therefore not found in the other disciplines, and there is considerably greater reliance on prefabricated structures than in the other fields, possibly reflecting the dependence of engineering rhetoric on visual representation where formulas and graphs are linked in routinely patterned, almost formulaic ways.

There was also considerable disciplinary specificity in the four-word bundles themselves. Table 6 shows the 30 most commonly used bundles in the four fields in frequency order, with just four items occurring in all four disciplines (bolded) and a handful in three disciplines (shaded).

While on the other hand, in the case of, as well as the, and at the same time occur in each of these disciplines, different fields seem to draw on almost completely different sets of items. More than half the items in each list do not occur at all in any other discipline, and only 30 percent of the strings in each discipline are found in two other fields. Applied linguistics has 29 items in the top 50 that do not occur in any of the other lists, and electrical engineering has 28 . The greatest affinity is between broadly cognate fields, as business studies and applied linguistics share 18 items, and biology and electrical engineering share 16. These contrasts perhaps reflect something of the argument patterns in the two domains, with those in the first group largely connecting aspects of argument and those in the second group avoiding authorial presence while pointing to graphs and findings.

A similar picture emerges with the forms and functions of these bundles. While a noun phrase with of- fragment is the most common structure overall, composing about a quarter of all forms in the corpus, social scientists made far greater use of bundles beginning with a prepositional phrase, typically indicating logical relations between propositional elements:

(8) We generated multi-item scales on the basis of previous measures, a review of the relevant literature, and interviews with marketing and purchasing personnel. ...such transformations should be studied in terms of the semantic and ideological transformations they entail.

This form often assists writers to discursively explore possibilities and elaborate relationships in argument. In contrast, the science and engineering 
Table 6. Most Frequent 30 Four-Word Bundles in Four Disciplines (Hyland, 2008b: p 12)

\begin{tabular}{|c|c|c|c|}
\hline Biology & Electrical engineering & Applied linguistics & Business studies \\
\hline $\begin{array}{l}\text { in the presence of } \\
\text { in the present study } \\
\text { on the other hand } \\
\text { the end of the } \\
\text { is one of the } \\
\text { at the end of } \\
\text { it was found that } \\
\text { at the beginning of } \\
\text { as well as the } \\
\text { as a result of } \\
\text { it is possible that } \\
\text { are shown in figure } \\
\text { was found to be } \\
\text { be due to the } \\
\text { in the case of } \\
\text { is shown in figure } \\
\text { the beginning of the } \\
\text { the nature of the } \\
\text { the fact that the } \\
\text { may be due to } \\
\text { are summarized in table } \\
\text { has been shown to } \\
\text { an important role in } \\
\text { at room temperature for } \\
\text { at the same time } \\
\text { can be used to } \\
\text { in the absence of } \\
\text { as shown in figure } \\
\text { with respect to the } \\
\text { used in this study }\end{array}$ & $\begin{array}{l}\text { on the other hand } \\
\text { as shown in figure } \\
\text { in the case of } \\
\text { is shown in figure } \\
\text { it can be seen } \\
\text { as shown in fig } \\
\text { is shown in fig } \\
\text { can be seen that } \\
\text { can be used to } \\
\text { the performance of the } \\
\text { as a function of } \\
\text { is based on the } \\
\text { with respect to the } \\
\text { is given by equation } \\
\text { the effect of the } \\
\text { the magnitude of the } \\
\text { at the same time } \\
\text { in this case the } \\
\text { it is found that } \\
\text { the size of the } \\
\text { be seen that the } \\
\text { the accuracy of the } \\
\text { as well as the } \\
\text { the same as the } \\
\text { is one of the } \\
\text { a function of the } \\
\text { as a result the } \\
\text { the results of the } \\
\text { in the form of } \\
\text { is assumed to be }\end{array}$ & $\begin{array}{l}\text { on the other hand } \\
\text { at the same time } \\
\text { in terms of the } \\
\text { on the basis of } \\
\text { in relation to the } \\
\text { in the case of } \\
\text { in the present study } \\
\text { the end of the } \\
\text { the nature of the } \\
\text { in the form of } \\
\text { as well as the } \\
\text { at the end of } \\
\text { the fact that the } \\
\text { in the context of } \\
\text { is one of the } \\
\text { in the process of } \\
\text { the results of the } \\
\text { in terms of their } \\
\text { to the fact that } \\
\text { in the sense that } \\
\text { the relationship between the } \\
\text { at the beginning of } \\
\text { the role of the } \\
\text { of the present study } \\
\text { as a result of } \\
\text { one of the most } \\
\text { can be seen as } \\
\text { it is important to } \\
\text { it should be noted } \\
\text { on the one hand }\end{array}$ & $\begin{array}{l}\text { on the other hand } \\
\text { in the case of } \\
\text { at the same time } \\
\text { at the end of } \\
\text { on the basis of } \\
\text { as well as the } \\
\text { the extent to which } \\
\text { the end of the } \\
\text { significantly different from zero } \\
\text { are more likely to } \\
\text { the relationship between the } \\
\text { the results of the } \\
\text { the other hand the } \\
\text { in the context of } \\
\text { as a result of } \\
\text { the performance of the } \\
\text { is positively related to } \\
\text { are significantly different from } \\
\text { in terms of the } \\
\text { the degree to which } \\
\text { in the long run } \\
\text { in the united states } \\
\text { the nature of the } \\
\text { the total number of } \\
\text { the size of the } \\
\text { in the number of } \\
\text { it is important to } \\
\text { the standard deviation of } \\
\text { with respect to the } \\
\text { of the number of } \\
\text { a }\end{array}$ \\
\hline
\end{tabular}


texts employed about four times more passive bundles, often followed by a prepositional phrase marking a locative or logical relation, to either guide readers through the text (10) or identify the basis for an assertion (11):

(9) The experiment setup is shown in Figure 4.13. All important events for pot trials are summarized in Table 4.11. (Bio)

(10) This apparent stability might be due to the complexing of plasma/serum DNA with proteins in the circulation. The measurement is based on the evaluation of infrared images produced by thermal waves.

One major disciplinary difference in the distribution of functions is the greater concentration of research-oriented bundles in the science and engineering texts, a preference that amounted to almost half of all bundles in the science/technology corpora. Once again, this imparts a greater real-world, laboratory-focused sense to writing in the hard sciences, contributing to the description or specification of research objects or contexts:

(11) The structure of the coasting-point identification model (see fig 5.6) can be divided into the following areas for description.

The size of the perforations becomes progressively smaller towards the base of the apparatus.

More than half of all cases, however, depicted research procedures, showing the ways that experiments and research were conducted:

(12) The DNA was precipitated in the presence of 2.5 volumes of ethanol and 0.1 volume of $3.0 \mathrm{M}$ sodium acetate $\mathrm{pH}$.

Transmission phase angle modulation can be used to increase the stability of the system, by maintaining the angle at a low value.

The social science texts, on the other hand, contained more than twice as many participant-oriented bundles as writers sought to establish their claims through more explicit evaluation and reader engagement. Here personal credibility and explicitly getting behind arguments play a far greater part in creating a convincing discourse:

(13) Such a dilemma may be due to the fact that they generally are unable to get support on English difficulties.

Ventures with superior performance are more likely to keep the original designs or even develop toward separate entities.

In the sciences, participant bundles largely sought to engage readers, explicitly marking the presence of the "reader-in-the-text" (Thompson \& Thetela, 1995, 103) through the use of directives (Hyland, 2002): 
(14) In other words, although mixtures of zero al exists, it is necessary to carefully optimize the material parameters associated with the rotational viscosity.

It should be noted that the extracted MAPs are associated with the polymerized tubulin.

Here the writer pulls the audience into the discourse at critical points to guide them to particular interpretations, typically by the use of a modal of obligation or a predicative adjective expressing the writer's judgment of necessity/importance.

\section{PEDAGOGIC ISSUES}

While the description of common lexical bundles can help us understand something of the features of academic writing and how disciplinary arguments are accomplished in different contexts, their study can also inform pedagogy (e.g., Meunier \& Granger, 2008). Bundles are familiar to writers and readers who regularly participate in a particular discourse, their very naturalness signaling competent participation in a given community. Conversely, this means that the absence of such clusters reveal the lack of fluency of a novice or newcomer to that community. Haswell (1991), for example, suggested the following:

There can be little doubt that as writers mature they rely more and more on collocations and that the lesser use of them accounts for some characteristic behaviour of apprentice writers. (p. 236)

The study of high-frequency strings and their possible variations may thus have great pedagogic value to teachers of English for academic purposes (EAP).

Research indicates, however, that the bundles used by novices and students differ markedly from those in professional academic writing (e.g., Chen \& Baker, 2010; Cortes, 2004; Hyland, 2008a; Scott \& Tribble, 2006). Studies have found, for example, that Chinese writers have difficulties in controlling this feature of academic writing (Lee \& Chen, 2009), either overusing particular connectors, such as first of all, on the other hand, and in a nutshell, compared with English writers (Milton, 1998), or otherwise demonstrating a lack of fluency (Ma 2009; Wei, 2007; Xu, 2007). Schmitt et al. (2004), however, found that relatively proficient EAP learners seem to already know a considerable number of high-frequency formulaic sequences and that they enhanced this knowledge over a 3-month course. Similarly, Li and Schmitt's (2009) Chinese case study student acquired 166 new lexical phrases during her one-year MA course.

It is possible, then, for bundles to be taught in EAP classrooms, although to date very little by way of practical applications has been published. Results, moreover, have generally been mixed. While Weber (2001) was able to use concordancing methods to teach her L2 law students key lexical items which included bundles, Cortes (2006) found her short course presenting bundles 
to undergraduate history students was not long enough to make a significant impact in their production. Jones and Haywood (2004), however, successfully introduced their intermediate level L2 students to frequent academic sequences in an intensive presessional EAP course. Beginning with reading texts flooded with core bundles of various lengths and using noticing activities which focused on concordance lines, the teachers then required learners to produce the sequences in cause-effect and problem-solution essays and in gapped writing tasks. Following pre- and post tests, these authors reported that through instruction and repeated exposure, "most students had shown greater awareness of formulaic sequences used as whole units, and a few students were able to us certain formulaic sequences accurately and appropriately in their essays" (Jones \& Haywood, 2004, p. 290).

The recent publication of an empirically derived Academic Formulas List (Simpson-Vlach \& Ellis, 2010) provides an impetus to further classroom practice in this area. Classified by adopting Biber, Conrad, and Cortes's (2003, 2004) pragmatic functions and identified from several academic corpora using statistical and qualitative methods, the list offers teachers a pedagogically useful inventory of sequences for speech and writing across a range of academic disciplines. While this may prove to be an important aid to instruction, work remains to be done on how best to make use of this resource.

\section{CONCLUSIONS}

Multiword expressions are an important defining feature of academic discourse and a significant component of fluent linguistic production. For these reasons there has been considerable interest in the last decade in identifying and categorizing bundles in order to characterize particular genres and harness the potential of common strings for successful language learning. Although issues of identification remain and studies suggest that corpus data on its own may be a poor indication of whether bundles are stored as chunks in the mind (Schmitt, Grandage, \& Adolphs, 2004), their very frequency in academic genres testifies that they constitute an important element of scholarly rhetorical competence. The ubiquity of these features suggests that gaining control of academic discourse requires a sensitivity to expert users' preferences for certain sequences of words over others that might seem equally possible. So, if learning to use the more frequent fixed phrases of a discipline can contribute to gaining a communicative competence in a field of study, there are advantages to identifying these bundles to better help learners acquire the specific rhetorical practices of their communities.

\section{ANNOTATED BIBLIOGRAPHY}

Biber, D. (2006). University language: A corpus-based study of spoken and written registers. Amsterdam, the Netherlands: John Benjamins.

Chapter six has a good discussion of bundles with definitional criteria, formal and functional categories, and an analysis of textbooks and classroom teaching. 
Biber, D., Conrad, S., \& Cortes, V. (2004). If you look at ... lexical bundles in university teaching and textbooks. Applied Linguistics, 25, 371-405.

A presentation of a functionally derived classification of academic bundles.

Hyland, K. (2008). As can be seen: Lexical bundles and disciplinary variation. English for Specific Purposes, 27, 4-21.

A cross-genre analysis of a large corpus of academic writing distinguished by discipline.

Simpson-Vlach, R., \& Ellis, N. (2010). An academic formulas list: New methods in phraseology research. Applied Linguistics, 31, 487-512.

An empirically derived proposal for a pedagogically useful list of multiword bundles derived from spoken and written academic genres in four broad fields of inquiry; a good starting point for teaching purposes.

\section{REFERENCES}

Altenberg, B. (1993). Recurrent word combinations in spoken English. In J. D. Arcy (Ed.), Proceedings of the Fifth Nordic Association for English Studies Conference (pp. 17-27). Reykjavik: University of Iceland.

Altenberg, B. (1998). On the phraseology of spoken English: The evidence of recurrent word-combinations. In A. Cowie (Ed.), Phraseology: Theory, analysis, and applications (pp. 101-122). Oxford, UK: Oxford University Press.

Barlow, M. (2004). Collocate [Computer software]. Houston, TX: Athelstan.

Biber, D. (2006). University language: A corpus-based study of spoken and written registers. Amsterdam, the Netherlands: John Benjamins.

Biber, D. (2009). A corpus-driven approach to formulaic language in English: Multi-word patterns in speech and writing. International Journal of Corpus Linguistics, 14, 275-311.

Biber, D., \& Barbieri, F. (2007). Lexical bundles in university spoken and written registers. English for Specific Purposes, 26, 263-286.

Biber, D., Conrad, S., \& Cortes, V. (2003). Towards a taxonomy of lexical bundles in speech and writing. In A. Wilson, P. Rayson, \& T. McEnery (Eds.), Corpus linguistics by the lune: A festschrift for Geoffrey Leech (pp. 71-92). Frankfurt, Germany: Peter Lang.

Biber, D., Conrad, S., \& Cortes, V. (2004). If you look at ... lexical bundles in university teaching and textbooks. Applied Linguistics, 25, 371-405.

Biber, D., Johansson, S., Leech, G., Conrad, S., \& Finegan, E. (1999). Longman grammar of spoken and written English. Harlow, UK: Pearson.

Butler, C. (1998). Collocational frameworks in Spanish. Journal of Corpus Linguistics, 3, $1-32$.

Chen, Y.-H., \& Baker, P. (2010). Lexical bundles in L1 and L2 student writing. Language, learning and technology, 14, 30-49.

Cheng, W. (2007). Concgramming: A corpus-driven approach to learning the phraseology of discipline-specific texts. CORELL: Computer Resources for Language Learning, 1, 2235 .

Cheng, W., Greaves, C., \& Warren, M. (2006). From n-gram to skipgram to concgram. International Journal of Corpus Linguistics, 11, 411-433.

Cheng, W., Greaves, C., Sinclair, J., \& Warren, M. (2007). Uncovering the extent of the phraseological tendency: Towards a systematic analysis of concgrams. Applied Linguistics, 30, 236-252.

Cortes, V. (2004). Lexical bundles in published and student disciplinary writing: Examples from history and biology. English for Specific Purposes, 23, 397-423. 
Cortes, V. (2006). Teaching lexical bundles in the disciplines: An example from a writing intensive history class. Linguistics and Education, 17, 391-406.

Cortes, V. (2008). A comparative analysis of lexical bundles in academic history writing in English and Spanish. Corpora, 3, 43-58.

Cortes, V., \& Csomay, E. (2007). Positioning lexical bundles in university lectures. In M. Campoy \& M. Luzon (Eds.), Spoken corpora in applied linguistics (pp. 55-77). New York, NY: Peter Lang.

Coxhead, A., \& Byrd, P. (2007). Preparing writing teachers to teach the vocabulary and grammar of academic prose. Journal of Second Language Writing, 16, 129-147.

De Cock, S. (1998). A recurrent word combination approach to the study of formulae in the speech of native and non-native speakers of English. International Journal of Corpus Linguistics, 3, 59-80.

Ellis, N., Simpson-Vlach, R., \& Maynard, C. (2008). Formulaic language in native and second language speakers: Psycholinguistics, corpus linguistics, and TESOL. TESOL Quarterly, 42, 375-396.

Greaves, C. (2009). Concgram 1.0: A phraseological search engine. Amsterdam, the Netherlands: John Benjamins.

Halliday, M. A. K. (1994). Functions of language (2nd ed.). London, UK: Edward Arnold.

Haswell, R. (1991). Gaining ground in college writing: Tales of development and interpretation. Dallas, TX: Southern Methodist University Press.

Hoey, M. (2005). Lexical priming: A new theory of words and language. London, UK: Routledge.

Hyland, K. (2002). Directives: Argument and engagement in academic writing. Applied Linguistics, 23, 215-239.

Hyland, K. (2008a). Academic clusters: Text patterning in published and postgraduate writing. International Journal of Applied Linguistics, 18, 41-62.

Hyland, K. (2008b). As can be seen: Lexical bundles and disciplinary variation. English for Specific Purposes, 27, 4-21.

Hyland, K., \& Milton, J. (1997). Hedging in L1 and L2 student writing. Journal of Second Language Writing, 6, 183-206.

Hyland, K., \& Tse, P. (2005). Hooking the reader: A corpus study of evaluative that in abstracts. English for Specific Purposes, 24, 123-139.

Jones, M., \& Haywood, S. (2004). Facilitating the acquisition of formulaic sequences. In N. Schmitt (Ed.), Formulaic sequences (pp. 269-300). Amsterdam, the Netherlands: John Benjamins.

Kim, Y. (2009). Korean lexical bundles in conversation and academic texts. Corpora, 4: 135-165.

Li, J., \& Schmitt, N. (2009). The acquisition of lexical phrases in academic writing: A longitudinal case study. Journal of Second Language Writing, 18, 85-102.

Lee, D., \& Chen, S. X. (2009). Making a bigger deal of the smaller words: Function words and other key items in research writing by Chinese learners. Journal of Second Language Writing, 18, 281-296.

Ma, G. H. (2009). A study of four-word lexical bundles in English major students' timed writing. Foreign Language Teaching and Research, 41, 54-60.

Meunier, F., \& Granger, S. (2008). Phraseology in foreign language learning and teaching. Amsterdam, the Netherlands: John Benjamins.

Milton, J. (1998). Exploiting L1 and interlanguage corpora in the design of an electronic language learning and production environment. In S. Granger (Ed.), Learner English on computer. London, UK: Longman.

Nesi, H., \& Basturkmen, H. (2006). Lexical bundles and discourse signaling in academic lectures. International Journal of Corpus Linguistics, 11, 283-304.

Pang, W. (2010). Lexical bundles and the construction of an academic voice: A pedagogical perspective. Asian EFL Journal, 47, 1-13.

Renouf, A., \& Sinclair, J. (1991). Collocational frameworks in English. In K. Aijmer \& B. Altenberg (Eds.), Advances in corpus linguistics (128-143). Amsterdam, the Netherlands: Rodopi. 
Schmitt, N., Dornyei, Z., Adolphs, S., \& Durow, V. (2004). Knowledge and acquisition of formulaic sequences. In N. Schmitt (Ed.), Formulaic sequences (55-86). Amsterdam, the Netherlands: John Benjamins.

Schmitt, N., Grandage, S., \& Adolphs, S. (2004). Are corpus-derived recurrent clusters psychologically valid? In N. Schmitt (Ed.), Formulaic sequences (pp. 127-151). Amsterdam, the Netherlands: John Benjamins.

Scott, M. (2008). WordSmith Tools, Version five [Computer software]. Liverpool, UK: Lexical Analysis Software.

Scott, M., \& Tribble, C. (2006). Textual patterns. Amsterdam, the Netherlands: John Benjamins.

Scollon, R., \& Scollon, S. (2001). Intercultural communication (2nd ed.). Oxford, UK: Blackwell.

Simpson, R. (2004). Stylistic features of academic speech: The role of formulaic expressions. In T. Upton \& U. Connor (Eds.), Discourse in the professions: Perspectives from corpus linguistics (pp. 37-64). Amsterdam, the Netherlands: John Benjamins.

Simpson, R., \& Mendis, D. (2003). A corpus-based study of idioms in academic speech. TESOL Quarterly, 3, 419-441.

Simpson-Vlach, R., \& Ellis, N. (2010). An academic formulas list: New methods in phraseology research. Applied Linguistics, 31, 487-512.

Sinclair, J. (1991). Corpus, concordance, collocation. Oxford, UK: Oxford University Press.

Swales, J. (1990). Genre analysis: English in academic and research settings. Cambridge, UK: Cambridge University Press.

Thompson, G., \& Thetela, P. (2001). The sound of one hand clapping: the management of interaction in written discourse. Text, 15, 103-127.

Tracy-Ventura, N., Cortes, V., \& Biber, D. (2007). Lexical bundles in speech and writing. In G. Parodi (Ed.), Working with Spanish corpora (pp. 217-230). London, UK: Continuum.

Weber, J.-J. (2001). A concordance and genre-informed approach to ESP essay writing. ELTJ, 55, 14-20.

Wei, N. X. (2007). Phraseological characteristics of Chinese learners' spoken English: Evidence of lexical chunks from COLSEC. Modern Foreign Languages, 30, 281-291.

Wray, A. (2002). Formulaic language and the lexicon. Cambridge, UK: Cambridge University Press.

Xu, J. J. (2007). Discourse management chunks in Chinese college learners' English speech: A spoken corpus-based study. Foreign Language Teaching and Research, 39, $437-443$. 